\title{
The Effect of Different Rearing Conditions on Muscle Characteristics in Broilers of Two Commercial Lines - A Light Microscopic Study
}

\author{
Polak Magdalena ${ }^{1}$, Przybylska-Gornowicz Barbara ${ }^{2}$ and Faruga Andrzej ${ }^{1}$ \\ ${ }^{1}$ Department of Poultry Science \\ ${ }^{2}$ Department of Histology and Embryology, Faculty of Veterinary Medicine; \\ University of Warmia and Mazury in Olsztyn, Poland
}

\begin{abstract}
A comparative histological and morphometric study based on selected skeletal muscles - musculus pectoralis superficialis and musculus gastrocnemius - in two lines of meat-type chickens, Anak Titan and Isa 215, was performed to detect potential differences regarding the effect of three production systems (chickens raised indoors in a conventional facility, indoors with limited outdoor access and outdoors with an umbrella roof) on muscle structure. The muscle fiber size was found to be affected by the production system, while the impact of the breeding line was less apparent. Disseminated fiber degeneration occurred more frequently in both examined muscles of Isa chickens raised outdoors. Necrotic fibers were very often infiltrated by mononuclear cells and underwent phagocytosis. The intensity of abnormal changes in muscle structure, including tiny fibers, fibers with hyaline cytoplasm and fibers with central nuclei, was substantially higher in chickens having outdoor access. This trend was particularly noticeable in musculus pectoralis superficialis and within the Isa 215 line. This indicates that it is more difficult for chickens of this line to adapt to changing environmental conditions. Significant changes observed in both muscles of birds raised outdoors can be considered highly undesirable with respect to the breeding objectives and breeding strategies for meat-type chickens. Environmental factors were found to play a more important role in chickens of the highly selected Isa 215 line, thus pointing to their worse adaptability to the less stable outdoor conditions. Furthermore, the present results suggest that the indoor housing system with access to an outdoor area can be an alternative to the traditional production system with regard to Anak Titan chickens.
\end{abstract}

Key words: histology, meat-type chickens, muscle, rearing conditions

J. Poult. Sci., 47: 125-132, 2010

\section{Introduction}

Modern poultry production systems are usually based on intensive chicken rearing. Systems that ensure the welfare of birds is safeguarded, including litter-based housing, low stocking density, free range, traditional farming with limited or free access to the outdoors, are much less popular (Anders, 2002).

The intensive rearing of highly selected fast-growing broilers confined indoors at high stocking density per square meter of floor area is most profitable, due to high feed costs and low market prices offered for live birds. The risk of disease occurring or spreading (including infections with the highly pathogenic avian influenza virus) is also minimized under intensive farming conditions. However, intensive chicken production causes certain problems. The natural behaviors of birds cannot be

Received: June 4, 2009, Accepted: December 4, 2009

Released Online Advance Publication: January 25, 2010

Correspondence: Prof. B. Przybylska-Gornowicz, Department of Histology and Embryology UWM, str. Oczapowskiego 13, 10-713 Olsztyn, Poland. (E-mail: przybylb@gmail.com) expressed, which leads to physical and psychological discomfort reflected in lower production results and a considerable deterioration of meat quality, including the occurrence of exudative meat and muscle fiber dystrophy (Kołacz and Bodak, 1999; Kołacz, 2004; Le Bihan-Duval et al., 2008). This causes concern among producers and consumers who claim that the taste and processing suitability of poultry meat produced through intensive farming are worse, compared with meat from chickens reared in extensive conditions. Therefore, the proposed alternatives, although more expensive and labor-consuming, are gaining in popularity, especially that poultry meat producers are forced to comply with animal welfare guidelines.

Another important issue in poultry production is a much higher incidence of pathological changes in breast muscle fibers observed in fast-growing chickens, compared with slow-growing birds (Wilson et al., 1990; Kłosowska et al., 1998; Mitchell, 1999; Bogucka et al., 2001; Witkiewicz et al., 2004; Wattanachant et al., 2005). In addition, highly selected meat-type chickens show poor adaptability, which results in muscle damage in response to stress. Degenerative changes in muscles may be caused 
by a variety of stressors which affect the neuro-hormonal system, leading to physiological and morphological disorders in birds. One of the stress factors causing muscular lesions in highly selected meat-type chickens is psychomotor stress (Soike and Bergmann, 1998a). The susceptibility to stress of broiler chickens is affected by the line and mode of selection (MacRae et al., 2006, 2007).

The quality of poultry raw material, related to muscle structure, is dependent on two factors, i.e. the genetic potential of birds and husbandry conditions. This issue has not been discussed at length in literature. The objective of the present study was to determine the effect of three production systems (broilers raised indoors in a conventional facility, indoors with limited outdoor access, outdoors with an umbrella-shaped roof) on the histological structure of selected muscles in meat-type chickens of two lines.

\section{Materials and Methods}

\section{Experimental Birds, Climate and Production Systems (Rearing Conditions)}

The experimental materials comprised two lines of broiler chickens known under the trade names of Anak Titan (A) and Isa 215 (Is). The experimental procedure was approved by the Local Ethics Committee at the University of Warmia and Mazury in Olsztyn (Opinion no $36 / N)$, and it complied with the universally accepted broiler production standards. One day - old broiler chickens of the two lines were obtained from the Czarne Błoto Hatchery and housed at the Instructional Farm of the Department of Poultry Science in Olsztyn (NE Poland, $53^{\circ} 43^{\prime} \mathrm{N}$ and $20^{\circ} 30^{\prime} \mathrm{E}$ ). The experiment was conducted during summer months (August-September), with mean air temperature of $17.5^{\circ} \mathrm{C}\left(8.5^{\left.-27.5^{\circ} \mathrm{C}\right)}\right.$ in August and $12.2^{\circ} \mathrm{C}\left(2.0^{-} 27.5^{\circ} \mathrm{C}\right)$ in September, and mean relative humidity of $79.9 \%$ (59-97\%) and 85.6\% (73-97\%), respectively. From 1 to 23 days of age, all chickens were kept on deep litter in a windowless house with light control. On day 24 , birds of the two lines were randomly divided into three groups, as follows:

1. groups I A and I Is (control) - chickens raised indoors, in a windowless house with mean air temperature of $21.5^{\circ} \mathrm{C}\left(17.0-26.0^{\circ} \mathrm{C}\right)$, constant humidity of $60 \%$ and artificial light intensity of $15 \mathrm{~lx}$ with L:D 18:6 ( $1^{\text {st }}-5^{\text {th }}$ day of the experiment), L:D 20:4 $\left(6^{\text {th }}-13^{\text {th }}\right.$ day of the experiment) and L:D 22:02 ( $14^{\text {th }}-24^{\text {th }}$ day of the experiment).

2. groups II A and II Is - chickens raised indoors, in a house with windows and with outdoor access. Mean air temperature in the house was $22.1^{\circ} \mathrm{C}\left(14.2^{-}\right.$ $32.4^{\circ} \mathrm{C}$ ), and relative humidity was $52.9 \%$ (31.0$71.0 \%)$. Chickens could use the range area with mean temperature of $19.5^{\circ} \mathrm{C}\left(11.0-29.2^{\circ} \mathrm{C}\right)$ and relative humidity of $59.3 \%(50.0-72.0 \%)$, between 7 : 30 a.m. and 7: 00 p.m.

3. groups III A and III Is - chickens raised outdoors, in a shelter with an umbrella-shaped roof. Mean temperature of $21.9^{\circ} \mathrm{C}\left(12.7-33.6^{\circ} \mathrm{C}\right)$ and relative humidity of $48.8 \%(35.0-62.0 \%)$. Chickens could use the range area with mean temperature of $19.6^{\circ} \mathrm{C}$ $\left(10.1-27.5^{\circ} \mathrm{C}\right)$ and relative humidity of $56.4 \%\left(39.0^{-}\right.$ 71.0\%), between 7: 30 a.m. and 7: 00 p.m.

The house with windows and the shelter with an umbrella roof are located along the east-west axis, with the range area in the south. The stocking density was up to 25 $\mathrm{kg}$ body weight per square meter of floor area in the house, and five birds per square meter in the range area. All chickens were fed complete starter, grower and finisher diets (Table 1). Feed and water was provided ad libitum to all experimental groups. The body weight of birds were monitored throughout the experiment (Fig.1).

\section{Histological Examinations}

The study was performed on twenty-four male chickens (six groups of four birds each) at the age of 48 days. The chickens were killed by decapitation. Approximately 1.2 $\mathrm{cm}^{3}$ samples of musculus pectoralis superficialis ( $m$. pectoralis) and musculus gastrocnemius ( $m$. gastrocnemius) were taken immediately after slaughter, from standardized regions of the right side of the bird. The samples were fixed in a $5 \%$ solution of trichloroacetic acid and postfixed in 95\% ethanol. The muscle blocks were

Table 1. Compound feed and rest period for their use (weeks)

\begin{tabular}{lrc}
\hline \hline \multicolumn{1}{c}{ Description } & Starter (1-3) & $\begin{array}{c}\text { Grower (4-5) } \\
\text { Finisher (6-7) }\end{array}$ \\
\hline Metabolizable energy, kcal & 2900 & 2935 \\
Total protein, \% & 22.10 & 19.50 \\
Crude fiber, \% & 3.20 & 3.10 \\
Lysine, \% & 1.43 & 1.13 \\
Methionine, \% & 0.57 & 0.54 \\
Methioine+cysteine, \% & 0.95 & 0.87 \\
Tryptophan, \% & 0.27 & 0.24 \\
Threonine, \% & 0.82 & 0.69 \\
Calcium, \% & 1.11 & 0.83 \\
Available phosphorus, \% & 0.47 & 0.43 \\
\hline
\end{tabular}

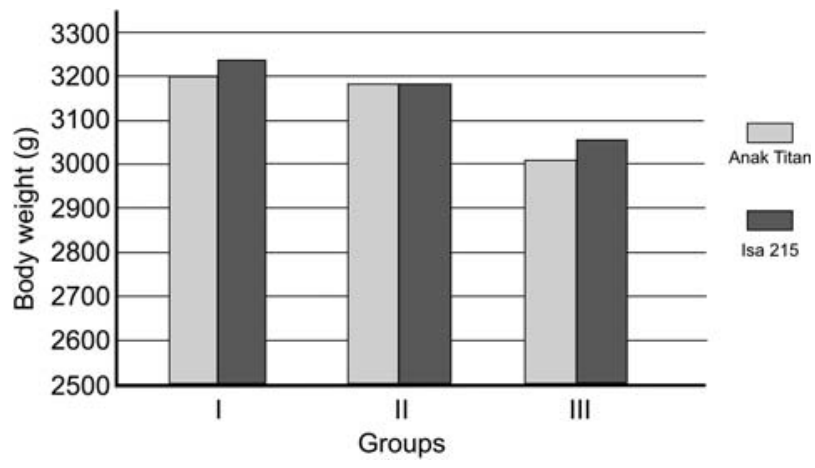

Fig. 1. Mean body weight of Anak Titan and Isa 215 lines of broilers at 48 days of age. 
paraffin-embedded. Longitudinal and cross paraffin sections $7 \mu \mathrm{m}$ thick were prepared and stained with hematoxylin-eosin (HE) and Mallory's method. A qualitative and descriptive evaluation of muscle pathology, and the determination of muscle fiber cross-sectional area were performed using $m$. pectoralis and $m$. gastrocnemius samples from four birds representing each line and production system.

\section{Morphometric Analyses}

Morphological analyses were performed on HE stained cross-sections of muscle fibers. Muscle fiber size was estimated in HE stained sections by measuring the crosssectional area. The area was measured using Olympus iTEM image analysis software. Images of 200 muscle fiber cross-sections, 100 of $\mathrm{m}$. pectoralis and 100 of $\mathrm{m}$. gastrocnemius for each bird, were randomly registered at an objective magnification of $\times 10$ using an Olympus DP-12 digital camera (Olympus Optical Co., Japan). The mean fiber cross-sectional area $\pm S E$ were calculated.

The percentages of muscle fibers with more than one central nucleus, fibers with hyaline cytoplasm, necrotic fibers and tiny fibers (with a cross-sectional area below $1300 \mu \mathrm{m}^{2}$ ) were determined. The percentages were calculated for 100 fibers of $m$. pectoralis and 100 fibers of $m$. gastrocnemius taken from each bird.

The data was analyzed using ANOVA followed by the Duncan's test.

\section{Results}

\section{Muscle Fiber Cross-sectional Area}

A comparison of the cross-sectional fiber area determined for $m$. pectoralis and $m$. gastrocnemius in Anak Titan and Isa 215 chickens showed that fiber size was affected by the production system, and that this effect varied depending on the muscle, whereas the impact of the breeding line was less apparent (Table 2). In general, in birds of both lines, the cross-sectional fiber area of $m$. pectoralis was smaller in groups having access to the outdoors $(P<0.01)$. The opposite trend was observed with respect to the cross-sectional fiber area of $m$. gastro- cnemius, which was found to be considerably larger in chickens raised with outdoor access $(P<0.01)$.

\section{Nuclear Distribution}

The percentage of $m$. pectoralis fibers with more than one central nucleus was affected by both chicken line and production system (Fig. 2G). The percentage of such fibers ranged between 7.8 and 16.4 in the $\mathrm{A}$ line, and between 2.5 and 14.2 in the Is line (Table 3 ). Within the A line, the percentage of fibers with more than one central nucleus was 16.4 in group I A, and it decreased to 7.8 in group II A and to 10.4 in group III A $(P<0.01)$. Within the Is line, the percentage of the above fibers showed the opposite tendency, increasing from the level of 2.5 in group I Is to 11.5 and 14.2 in group II Is and III Is, respectively $(P<0.01)$. As shown in Table 4 , no $m$. gastrocnemius fibers with more than one central nucleus were observed in chickens of the A line. In the Is line these fibers were present regardless of the production system, and their percentage was 7.0 in group I Is increased to 11.0 in group II Is, whereas in group III Is it increased to $28.0(P<0.01)$.

\section{Fibers with Hyaline Cytoplasm}

Within the A line, fibers with hyaline cytoplasm were present in $m$. pectoralis sections regardless of the production system (Table 3, Fig. 2C, 2F, 2H). The highest (42.5) percentage of fibers with hyaline cytoplasm was noted in group I A and the lowest (35.0) in group II A ( $P$ $<0.01)$. As regards $m$. gastrocnemius, the percentage of fibers with hyaline cytoplasm was as low as 2.0 in group I A, and it increased distinctly $(P<0.01)$ to 15.6 in chickens provided with limited outdoor access - group II A and to 22.2 in chickens raised outdoors-group III A (Table 4).

In chickens of the Is line, the percentage of fibers with hyaline cytoplasm in $m$. pectoralis sections was considerably lower $(P<0.01)$, compared with the A line and it increased only insignificantly in chickens raised with outdoor access (Table 3 ). In $m$. gastrocnemius sections, a noticeable increase $(P<0.01)$ in the percentage of these fibers was observed only in chickens kept under an umbrella-shaped roof (group III Is - 34.8), as compared

Table 2. Fiber cross-sectional area of the $m$. pectoralis superficialis and $m$. gastrocnemius of the Anak Titan and Isa 215 lines of broilers at 48 days of age raised indoors in a conventional facility (I) indoors with limited outdoor access (II) and outdoors with an umbrella roof (III)

\begin{tabular}{lcc}
\hline \hline \multirow{2}{*}{ Chicken line and production system } & M. pectoralis superficialis & M. gastrocnemius \\
\cline { 2 - 3 } & Mean fiber area $( \pm$ SE $)$ & Mean fiber area $( \pm$ SE $)$ \\
\hline I Anak Titan & $1984 \pm 423^{\mathrm{a}}$ & $1932 \pm 573^{\text {aef }}$ \\
II Anak Titan & $1445 \pm 352^{\mathrm{b}}$ & $2071 \pm 333^{\text {bef }}$ \\
III Anak Titan & $1445 \pm 352^{\text {cde }}$ & $2505 \pm 519^{\mathrm{c}}$ \\
I Isa 215 & $1740 \pm 261^{\text {dec }}$ & $1723 \pm 309^{\text {d }}$ \\
II Isa 215 & $1692 \pm 263^{\text {edc }}$ & $1969 \pm 395^{\text {eabf }}$ \\
III Isa 215 & $1558 \pm 334^{\mathrm{f}}$ & $2010 \pm 341^{\text {fabc }}$ \\
\hline
\end{tabular}

Fiber area $\left(\mu \mathrm{m}^{2}\right)$ are mean $\pm \mathrm{SE}(\mathrm{n}=100)$. The values marked with different letters are significantly different from each other $(P<0.01)$. 


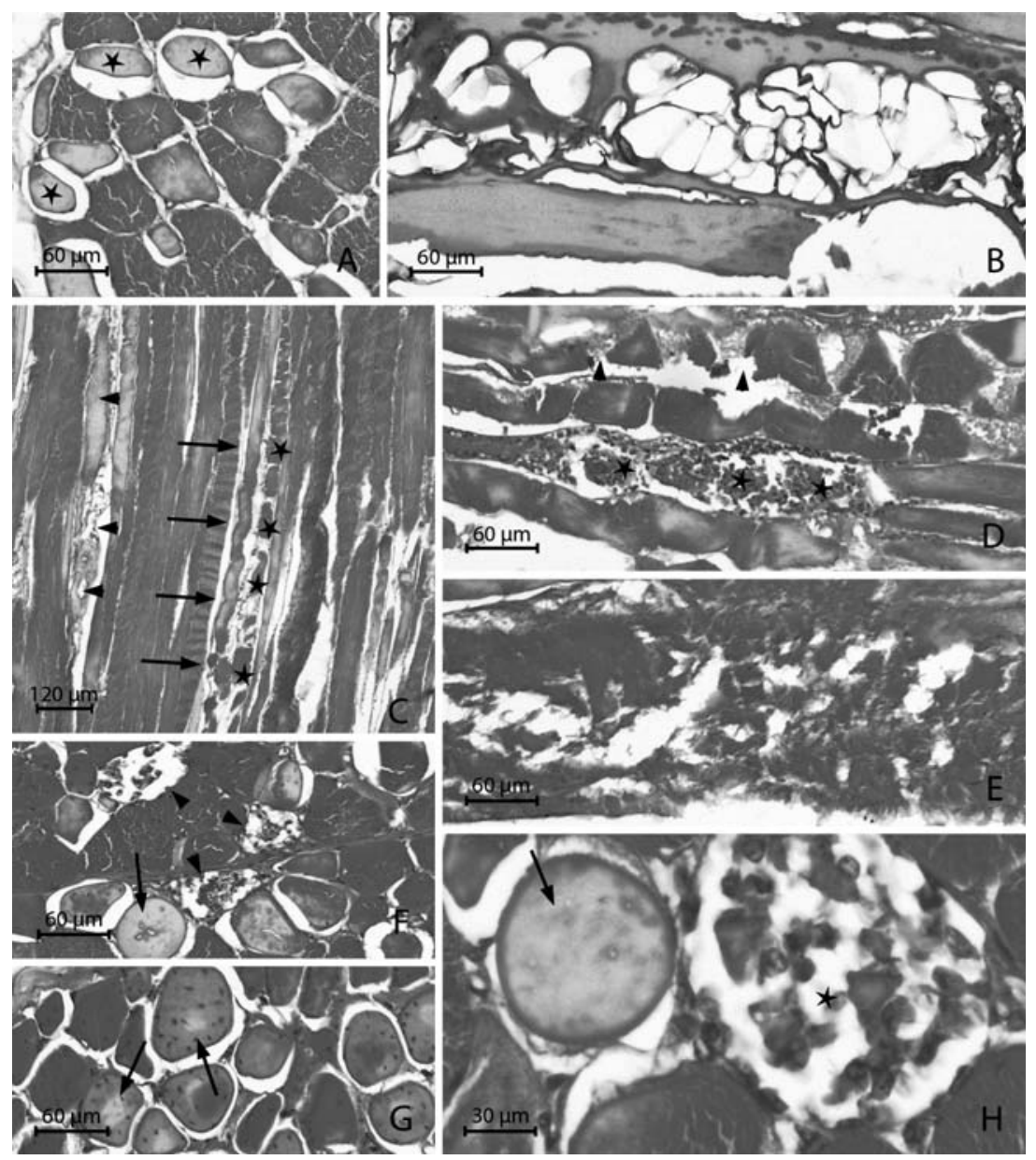

Fig. 2. Abnormal structure of fibers in the examined muscles of two lines of meat-type chickens raised in three production systems:

A. Muscle bundles showing fibers with hyaline cytoplasm (asterisks)note the changes in their area and fiber size variation. Anak line, m. gastrocnemius, group II A, H\&E.

B. Necrotic fibers exhibiting vacuolation. Anak line, $m$. pectoralis, group I A, H\&E.

C. Fibers with a hyper-contracted appearance (arrows), degenerating fibers (head of arrows), and fiber splitting (asterisks). Anak line, m. gastrocnemius, group II A, H\&E.

D. Muscle bundles showing fibers with segmental necrosis and phagocytosis of damaged part (asterisks), fibers splitting (head of arrows). Isa line, $m$. pectoralis, group III Is, H\&E.

E. Adhesion of damaged muscle fibers in the middle part of muscle bundles. Note the lack of muscle fiber integrity. Isa line, $m$. pectoralis, group II Is, H\&E.

F. Muscle bundles with necrotic fibers (head of arrows) and fibers with hyaline cytoplasm (arrows). Note the process of phagocytosis of necrotic fibers. Isa line, $m$. pectoralis, group III Is, H\& E.

G. Central nuclei in fibers with hyaline cytoplasm (arrows). Isa line, $m$. pectoralis, group I Is, H\&E.

H. Cross-section of muscle fibers. Note the presence of fibers with hyaline cytoplasm(arrow) and mononuclear cell phagocytosis of necrotic fibers (asterisk). Isa line, $m$. pectoralis, group III Is, H\& E. 
Table 3. Fibers with $>\mathbf{1}$ central nucleus and hyaline cytoplasm, and tiny and necrotic fibers of the m. pectoralis superficialis of the Anak Titan and Isa 215 lines of broilers at 48 days of age raised indoors in a conventional facility (I) indoors with limited outdoor access (II) and outdoors with an umbrella roof (III)

\begin{tabular}{ccccc}
\hline \hline $\begin{array}{c}\text { Chicken line and } \\
\text { production system }\end{array}$ & $\begin{array}{c}\text { Fibers with over } \\
\text { one central nucleus }\end{array}$ & $\begin{array}{c}\text { Fibers with hyaline } \\
\text { cytoplasm }\end{array}$ & Tiny fibers & Necrotic fibers \\
\hline I Anak Titan & $16.4 \pm 1.72^{\text {af }}$ & $42.5 \pm 11.03^{\mathrm{a}}$ & $5.8 \pm 2.29^{\text {ade }}$ & $0.2 \pm 0.18^{\mathrm{a}}$ \\
II Anak Titan & $7.8 \pm 1.21^{\text {bec }}$ & $35.0 \pm 2.26^{\mathrm{b}}$ & $1.8 \pm 0.21^{\mathrm{b}}$ & $0.1 \pm 0.14^{\mathrm{a}}$ \\
III Anak Titan & $10.4 \pm 1.80^{\mathrm{cbe}}$ & $38.0 \pm 13.67^{\mathrm{c}}$ & $3.9 \pm 0.33^{\text {cd }}$ & $0.2 \pm 0.18^{\mathrm{a}}$ \\
I Isa 215 & $2.50 \pm 0.48^{\mathrm{d}}$ & $16.6 \pm 1.26^{\mathrm{d}}$ & $4.4 \pm 0.34^{\mathrm{daec}}$ & $0.2 \pm 0.18^{\mathrm{a}}$ \\
II Isa 215 & $11.5 \pm 4.60^{\mathrm{ebc}}$ & $19.8 \pm 4.30^{\mathrm{e}}$ & $5.9 \pm 0.20^{\mathrm{ead}}$ & $0.4 \pm 0.18^{\mathrm{a}}$ \\
III Isa 215 & $14.2 \pm 2.07^{\mathrm{fae}}$ & $21.5 \pm 2.40^{\mathrm{f}}$ & $8.0 \pm 1.45^{\mathrm{f}}$ & $7.6 \pm 0.71^{\mathrm{b}}$ \\
\hline
\end{tabular}

Mean percentages of fibers. The values marked with different letters are significantly different from each other $(P<0.01)$.

Table 4. Fibers with $>\mathbf{1}$ central nucleus and hyaline cytoplasm, and tiny and necrotic fibers of the m. gastrocnemius of the Anak Titan and Isa 215 lines of broilers at 48 days of age raised indoors in a conventional facility (I) indoors with limited outdoor access (II) and outdoors with an umbrella roof (III)

\begin{tabular}{ccccc}
\hline \hline $\begin{array}{c}\text { Chicken line and } \\
\text { production system }\end{array}$ & $\begin{array}{c}\text { Fibers with over } \\
\text { one central nucleus }\end{array}$ & $\begin{array}{c}\text { Fibers with hyaline } \\
\text { cytoplasm }\end{array}$ & Tiny fibers & Necrotic fibers \\
\hline I Anak Titan & $0 \pm 0.00^{\mathrm{a}}$ & $2.0 \pm 1.36^{\mathrm{a}}$ & $9.3 \pm 0.94^{\mathrm{a}}$ & $0.3 \pm 0.24^{\mathrm{abcd}}$ \\
II Anak Titan & $0 \pm 0.00^{\mathrm{a}}$ & $15.6 \pm 5.79^{\mathrm{b}}$ & $5.5 \pm 2.13^{\mathrm{bec}}$ & $0.1 \pm 0.14^{\mathrm{bda}}$ \\
III Anak Titan & $0 \pm 0.00^{\mathrm{a}}$ & $22.2 \pm 4.16^{\mathrm{b}}$ & $7.1 \pm 1.10^{\mathrm{cb}}$ & $2.8 \pm 0.43^{\mathrm{c}}$ \\
I Isa 215 & $7.0 \pm 2.94^{\mathrm{b}}$ & $10.1 \pm 4.33^{\mathrm{bbe}}$ & $3.5 \pm 0.40^{\mathrm{dbe}}$ & $0.4 \pm 0.24^{\text {dabe }}$ \\
II Isa 215 & $11.0 \pm 2.93^{\mathrm{c}}$ & $11.4 \pm 7.30^{\mathrm{edb}}$ & $4.6 \pm 0.36^{\mathrm{edb}}$ & $0.8 \pm 0.73^{\text {eadb }}$ \\
III Isa 215 & $28.0 \pm 3.35^{\mathrm{d}}$ & $34.8 \pm 6.70^{\mathrm{f}}$ & $6.8 \pm 1.25^{\mathrm{f}}$ & $4.8 \pm 1.40^{\mathrm{f}}$ \\
\hline
\end{tabular}

Mean percentages of fibers. The values marked with different letters are significantly different from each other $(P<0.01)$.

with groups I Is and II Is (Table 4).

\section{Necrotic Fibers}

Fibers exhibiting segmental necrosis, abnormal shapes, enlargement, splitting, vacuolation and phagocytosis were observed in the analyzed muscle sections (Fig. 2B, 2C, 2 $\mathrm{D}, 2 \mathrm{~F}, 2 \mathrm{H})$. As shown in Table 3, with respect to $m$. pectoralis, the incidence of necrotic fibers was low in chickens of groups I A, II A, III A and I Is, II Is, while a high percentage of such fibers (above 7) was noted in group III Is chickens $(P<0.01)$. As regards $m$. gastrocnemius, the incidence of necrotic fibers was low in chickens of groups I A, II A, and I Is, II Is (Table 4). The percentage of necrotic fibers did not exceed one in these groups. However, in groups III A and III Is the proportion of necrotic fibers increased significantly $(P<0.01)$.

\section{Tiny Fibers}

Tiny fibers (Fig. 2A, 2F) were noted in $m$. pectoralis sections in all groups of both lines. The percentage of tiny fibers was affected by both chicken line and production system (Table 3). Within the A line, the percentage of tiny fibers in $m$. pectoralis sections was 5.8 in group I A and it decreased significantly $(P<0.01)$ to 1.8 in group II $\mathrm{A}$ and to 3.4 in group III A. The opposite tendency was observed in chickens of the Is line. The percentage of tiny fibers was 4.4 in group I Is, and it increased significantly $(P<0.01)$ to 5.9 in group II Is and to 8.0 in group III Is. As regards $m$. gastrocnemius, the percentage of tiny fibers was 9.3 in group I A and it decreased significantly $(P<$ $0.01)$ to 5.5 in group IIA and 7.1 in group III A. Within the Is line, the percentage of tiny fibers increased significantly $(P<0.01)$ from the level of 3.5 in group I Is to 4.6 and 6.8 in groups II Is and III Is, respectively (Table 4).

\section{Muscle Microstructure}

A detailed analysis of muscle microstructure was performed in chickens of both lines, raised in three different production systems. Particular attention was paid to the occurrence and intensity to pathological changes. The following factors were taken into account: muscle structure resulting from the presence of connective tissue, differences in fiber diameter, the presence and distribution of fibers with hyaline cytoplasm, fibers contracting in response to the applied procedure, fibers exhibiting vacuolation, split fibers, necrotic fibers and the degree of their desintegration, and infiltration by mononuclear cells accompanying necrotic fibers.

In $m$. pectoralis of Anak Titan line, endomysial connective tissue was thin, with numerous blood vessels, and the 
layer of perimysium was observed in all birds of groups II A and III A. In the muscles of I A chickens the perimysium was well-developed with abundant blood vessels. Differences in fiber size were noted in the muscles of all birds.

The incidence of hyaline fibers in the examined muscles was high. Hyaline fibers were randomly scattered in muscle fiber bundles or almost entirely made up muscle bundles (groups I A and II A). Few necrotic fibers were present in all birds of all groups within the Anak line. There were lymphocytes in some necrotic areas. Fiber splitting was observed incidentally. Some fibers exhibiting vacuolation were also noted (Fig. 2B).

In $m$. gastrocnemius of Anak Titan line, connective tissue (the endomysium and the perimysium) with numerous cells and blood vessels was visible in all birds, regardless of the production system. Birds of group I A showed a low incidence of hyaline fibers and numerous hyaline fibers was present in chickens of groups II A and III A. Hyaline fibers were widespread throughout all muscle bundles, irrespective of their number. Necrotic fibers occurred at low frequency in chickens of groups II A and III A, and were incidentally observed in some birds of group I A. Lymphocytes were seen in the necrotic area. Muscle fibers differed considerably in size (Table 2). Fiber splitting was observed in birds of all groups (Fig. 2A, 2C).

M. pectoralis of Isa 215 chickens was characterized by well-developed endomysial and perimysial connective tissue, with abundant blood vessels in all groups. The fibers were loosely arranged in muscle fiber bundles. A distinctive feature was the presence of numerous lymphocytes whose number was the highest in the connective tissue cells of Isa 215 chickens raised outdoors.

The incidence of hyaline fibers did not show marked differences. They formed small conglomerates within muscle bundles. Necrotic fibers were incidentally observed in chickens of groups I Is and II Is, and were a common feature of III Is birds. Numerous necrotic fibers were infiltrated by mononuclear cells. Split fibers were often observed, particularly in two individuals. Cases of adhesion between damaged muscle fibers were noted (Fig. $2 \mathrm{D}, 2 \mathrm{E}, 2 \mathrm{~F}, 2 \mathrm{G}, 2 \mathrm{H})$.

In m. gastrocnemius of Isa 215 line connective tissue comprised layers of well-developed endomysium and perimysium, irrespective of the production system. The frequency of occurrence of hyaline fibers varied markedly, depending on the group of birds. The number of fibers with hyaline was the highest in group III Is, lower in groups II Is, and the lowest in group I Is. The patterns of muscle fiber distribution differed among groups. Necrotic fibers were found in all groups, but their incidence was higher in group III Is, compared with groups I Is and II Is. Numerous lymphocytes were observed in necrotic areas. Fiber splitting was observed frequently.

\section{Discussion}

The results of this study revealed significant differences in the microstructure of $m$. pectoralis and $m$. gastrocnemius between two lines of chickens raised in three production systems. The findings reported by other authors differ considerably in this respect. According to Kłosowska (1984), the histological characteristics of poultry muscles change in response to environmental conditions, irrespective of genetic factors. On the other hand, experiments on turkeys proved a profound impact of genetic factors on changes in muscle structure (Sośnicki et al., 1991; Kłosowska et al., 1999). The results of studies on the effect exerted by different production systems also vary widely. Some authors point to a significant influence of the production system on skeletal muscle morphology (Burs et al., 2006), while other claims that there is no such a relationship (Sowińska, 2002). Burs et al. (2006) reported that the microstructure of $m$. pectoralis and $m$. gastrocnemius was affected by both the type of turkeys and the farming system (indoors and outdoors). These authors found that turkey-toms having access to the outdoors were characterized by more desirable muscle microstructure. Studies on geese have confirmed that histological changes in breast muscles are related to the origin of birds (Kłosowska et al., 1998; Bogucka et al., 2001). The present study revealed marked differences in muscle microstructure, dependent on the line of chickens, production system and the analyzed muscle.

A smaller cross-sectional fiber area of $m$. pectoralis was noted in chickens of both lines, having access to the outdoors. An increment in $m$. pectoralis mass results primarily from the hypertrophy of type IIB fibers (Goldspink and Yang, 1999; MacRae et al., 2007). These large-size fibers contribute to the growth of breast muscles (MacRae et al., 2007). Despite their considerable thickness, type IIB fibers can function well in birds kept indoors, since they are rarely used (Hughes and Schaffino, 1999). The decrease in fiber size, observed in this study, resulted from the increased motor activity of chickens. The rate of fiber growth was reduced to avoid the risk of insufficient diffusion of oxygen and metabolites (Soike and Bergmann 1998b; Mahon, 1999). At the same time, the increase in the number of damaged fibers is indicative of problems with muscle tissue adaptation to new conditions. Since breast muscle enlargement is dependent on fiber hypertrophy, a decrease in fiber size must be followed by a decrease in muscle mass, and degenerative changes in fibers must lead to a deterioration in muscle quality. The reverse effect was observed in $m$. gastrocnemius, where intensive motor activity resulted in fiber hypertrophy. Type I fibers making up $m$. gastrocnemius have a smaller diameter in broiler chickens raised indoors, due to oxidative metabolism characteristic of these muscle fibers (Hughes and Schaffino, 1999). An increase in fiber size is generally considered disadvantageous as it reduces the efficiency of oxidative metabolism which can lead to fiber 
damage (Soike and Bergmann, 1998b). An example may be an increase in the number of necrotic fibers, which in the present study was particularly evident in chickens of the Isa 215 line.

The most significant changes observed in this study were those indicating the occurrence of destructive processes within muscles. The intensity of pathological changes was estimated based on the presence of the following types of fibers: fibers with a cross-sectional area below $1300 \mu \mathrm{m}^{2}$, fibers with hyaline cytoplasm, fibers with central nuclei and necrotic fibers. The occurrence of such fibers is considered symptomatic of structural abnormalities, lesion and damage (Soike and Bergmann, 1998a; MacRae et al., 2006, 2007). The number of pathological changes was substantially higher in Isa line birds, particularly in those kept outdoors. Compared with the Anak Titan line, Isa 215 chickens are selected more for meat production, and are characterized by a faster growth rate.

It has been proposed that the location of myonuclei may be related to altered myofibrillar pressure (Goldspink, 1974) or to a larger fiber size in certain avian muscles (MacRae et al., 2006). Central nuclei were observed in both degenerated and less affected fibers (Pizzey and Barnard, 1983). In our study central nuclei were found primarily in fibers with hyaline cytoplasm, both in $m$. pectoralis and $m$. gastrocnemius sections. Their occurrence was closely correlated with line of chickens. Within the Anak Titan line, central nuclei were reported exclusively in $m$. gastrocnemius and their percentage was lower in birds raised with outdoor access. In birds of the Isa 215 line outdoor access increased the percentage of fibers with central nuclei, both in $m$. pectoralis and $m$. gastrocnemius. It should be emphasized that despite the presence of central nuclei in both normal and degenerating fibers, their role in poultry skeletal muscles has not been fully elucidated (MacRae et al., 2006).

Hyaline cytoplasm is one of the symptoms of muscle fiber degeneration (Nakada et al., 1998). In a study performed by MacRae et al. (2006), fibers with hyaline cytoplasm were the predominant type of abnormal fibers in broiler $m$. biceps femoris samples and were observed at low frequency in $m$. pectoralis. The present study showed more degenerating muscle fibers with hyaline cytoplasm in $m$. pectoralis samples in birds with outdoor access, regardless of the line. It should be stressed that there were significant difference between particular chickens in this respect. A tendency towards an increased occurrence of muscle fibers with hyaline cytoplasm in chickens provided with outdoor access was also observed in $m$. gastrocnemius samples, and it was more pronounced within the Isa line.

Pathological changes in muscle fibers in poultry, irrespective of the type of myopathy, show certain similarities (Sośnicki et al., 1989; MacRae et al., 2006). Histological examinations of poultry muscles have demonstrated that the frequency of occurrence of various pathologies is much higher in broilers than in layers (Soike and Bergmann, 1998a). The sources of muscle degeneration have not been investigated thoroughly, but one of them is the disproportion between the growth rate of birds and their muscles (Mahon, 1999). Damaged fibers are infiltrated by leukocytes and undergo necrosis (Kranen et al., 2000). Necrotic fibers are among the most common abnormalities reported in broiler chickens (Soike and Bergmann, 1998a; MacRae et al., 2006).

In the present study a common feature of the examined muscles was the occurrence of necrotic fibers. Our findings show that the number of necrotic fibers was higher in chickens having outdoor access. This trend was particularly noticeable in $\mathrm{m}$. pectoralis and within the Isa 215 line, which suggests that it is more difficult for chickens of this line to adapt to changing environmental conditions.

The changes observed in both muscles of chickens raised outdoors can be considered highly undesirable, from the perspective of the health of birds and the quality of the produced meat. Studies conducted to date indicate that dystrophic changes in muscle tissue are usually accompanied by the exudativeness of meat resulting from low water-holding capacity (Grabowski, 1993), which adversely affects the eating quality of meat. Another unfavorable feature of muscles is a high proportion of fibers with hyaline cytoplasm, whose presence contributes to the occurrence of pale, soft and exudative-like meat (Barbut et al., 2005)

The results of the present study confirm the existence of differences between the analyzed breeding lines of broiler chickens, and provide information on the effect of different farming systems on skeletal muscle characteristics. Our findings are in agreement with the results reported by Fanatico et al. (2008), who pointed to differences among genotypes and their efficiency and potential for alternative poultry production systems. It can be concluded that chickens of the Anak Titan and Isa 215 lines are not suited for outdoor production. Environmental factors were found to play a more important role in chickens of the highly selected Isa 215 line. The intensity of pathological changes observed in these birds is indicative of their worse adaptability to the less stable outdoor conditions. As regards Anak Titan line chickens, the indoor housing system with access to an outdoor area, despite certain disadvantages, can be considered a viable alternative to traditional farming.

\section{References}

Anders E. Poultry farming criteria according to the European marketing standards for poultry meat. Polish Poultry, 1: 1618. 2002.

Barbut S, Hang L and Marcone M. Effects of pale, normal and dark chicken breast meat on microstructure, extractable proteins, and cooking of marinated fillets. Poultry Science, 84: 779-802. 2005.

Bogucka J, Kłosowska D, Elminowska-Wenda G, Walasik K, Puchajda $\mathrm{H}$ and Grymuza D. Histopathological changes in musculus pectoralis superficialis of geese from different genetic groups. Scientific Annals of Polish Society of Animal Production, 57: 431-443. 2001. 
Burs M, Przybylska-Gornowicz B and Faruga A. Influence of breeding conditions and aims on the histology and ultrastructure of two muscles in turkeys. Veterinary Medicine Science \& Practice, 62: 1195-1199. 2006.

Fanatico AC, Pillai PB, Hester PY, Falcone C., Mench JA, Owens CM and Emmert JL. Performance, livability, and carcass yield of slow- and fast-growing chicken genotypes fed low-nutrient or standard diets and raised indoors or with outdoor access. Poultry Science, 87: 1012-1021. 2008.

Grabowski T. Poultry meat technology. pp. 25-40.WNT. Warszawa. 1993. (In polish)

Goldspink G. Development of muscle. In: Differentiation and growth of cells in vertebrate tissues. (Goldspink $\mathrm{G}$ ed.). pp. 69-99. Chapman and Hall, London. 1974.

Goldspink G and Yang SY. Muscle structure, development and growth. In: Poultry Meat Science. Poultry Science Symposium Series. (Richardson RI and Mead CG eds.). pp. 3-18. CAB International. Oxon. UK. 1999.

Hughes SM and Schaffino S. Control of muscle fiber size: a crucial factor in ageing. Acta Physiologica Scandinavica, 167: 307-312. 1999.

Kłosowska D. Histological and histochemical characteristics of muscle in pigs, cattle and poultry and their relationship with meat quality. Thesis for degree of associate professor. Vol. 31. pp. 1-111. University of Agriculture and Technology Press. Olsztyn. Poland. 1984.

Kłosowska D, Bernacki Z and Hejnowska M. Histopathological changes in musculus pectoralis superficialis in hens after the second egg-laying season. Scientific Annals of Polish Society of Animal Production, 36: 67-75. 1998.

Kłosowska D, Lewandowska M and Puchajda H. Histopathological changes in musculus pectoralis superficialis of the hens after second laying period. Scientific Annals of Polish Society of Animal Production, 45: 73-80. 1999.

Kranen RW, Lambooy E., Veerkamp CH, Van Kuppevelt TH and Veerkamp JH. Histological characterization of hemorrhages in muscles of broiler chickens. Poultry Science, 79: 110-116. 2000.

Kołacz R and Bodak E. Animal welfare and criteria for its evaluation. Veterinary Medicine - Science \& Practice, 53: 147-154. 1999.

Kołacz R. Directions of changes in poultry production systems in light of poultry welfare programs. Veterinary Magazine (Supplement Poultry IV) pp. 9-13. 2004.

Le Bihan-Duval E, Debut M, Berri C, Sellier N, SanteLhoutellier V, Jego Y and Beaumont C. Chicken meat Quality: genetic variability and relationship with growth and muscle characteristics. BMC Genetics, 18: 53-60. 2008.

MacRae VE, Mahon M, Gilpin S, Sandercock DA and Mitchell MA. Skeletal muscle fiber growth and growth-associated myopathy in the domestic chicken (Gallus domesticus). British Poultry Science, 47: 264-272. 2006.
MacRae VE, Mahon M, Gilpin S, Sandercock DA, Hunter RR and Mitchell MA. A comparison of breast muscle characteristics in three broiler great-grandparent lines. Poultry Science, 86: 382-385. 2007.

Mahon M. Muscle abnormalities - morphological aspects. In: Poultry Meat Science. (Richardson RI and Mead CG eds.) Poultry Science Symposium Series. Vol. 25. pp. 19-64. CABI publishing. Oxon. UK. 1999.

Mitchell MA. Muscle abnormalities-pathophysiological mechanisms. In: Poultry Meat Science (Richardson RI and Mead GC eds.), Poultry Science Symposium Series. Vol 25. pp. 65-98. CABI Publishing. Oxon. UK. 1999.

Nakada K., Mashima J, Yao Y, Miyazaki J and Hirabayashi T. Developmental stage-dependent expression of troponin $\mathrm{T}$ isoforms in chicken embryonic breast grafted on chorioallantoic membrane. Zoological Science, 15: 729-736. 1998.

Pizzey JA and Barnard EA. Structural changes in muscles of the dystrophic chicken. II. Progression of the histopathology in the pectoralis muscle. Neuropathology and Applied Neurobiology, 9: 149-164. 1983.

Soike D and Bergmann V. Comparison of skeletal muscle characteristics in chickens bred for meat or egg production. I. Histopathological and electron microscopic examination. Zentralblatt für Veterinärmedizin. Reihe A, 45: 161-167. 1998a.

Soike D and Bergmann V. Comparison of skeletal muscle characteristics in chickens bred for meat or egg production. II. Histochemical and morphometric examination. Zentralblatt für Veterinärmedizin. Reihe A, 45: 169-174. 1998b.

Sośnicki AA, Cassens RG, Vimini RJ and Greaser ML. Histopathological and ultrastructural alternations of turkey skeletal muscle. Poultry Science, 70: 349-357. 1991.

Sośnicki AA, Cassens RG, McIntyre DR, Vimini RJ and Greaser ML. Incidence of microscopically detectable degenerative characteristics in skeletal muscles of turkeys. British Poultry Science, 30: 69-80. 1989.

Sowińska J. Effect of production system, commercial type and pre-slaughter handling on selected blood parameters, the morphological picture of breast muscles and meat quality in turkeys. University of Warmia and Mazury Press. Olsztyn, Poland. 2002.

Wattanachant S, Benjakul S and Edward DA. Microstructure and thermal characteristics of Thai indigenous and broiler chicken muscles. Poultry Science, 84: 328-337. 2005.

Wilson BW, Nieberg PS, Buhr RJ, Kelly BJ and Schultz FT. Turkey muscle growth and focal myopathy. Poultry Science, 69: 1553-62. 1990.

Witkiewicz K, Kontecka H, Książkiewicz J, Szwaczkowski T and Perz W. Primal carcass parts and breast muscle microstructure in selected and non-selected ducks. Animal Science Papers and Reports, 22: 65-73. 2004. 